Contract No. and Disclaimer:

This manuscript has been authored by Savannah River Nuclear Solutions, LLC under Contract No. DE-AC09-08SR22470 with the U.S. Department of Energy. The United States Government retains and the publisher, by accepting this article for publication, acknowledges that the United States Government retains a non-exclusive, paid-up, irrevocable, worldwide license to publish or reproduce the published form of this work, or allow others to do so, for United States Government purposes. 


\title{
Pt and Pt/Ni "Needle" Eletrocatalysts on Carbon Nanotubes with High Activity for the ORR
}

\author{
Mark C. Elvington and Héctor R. Colón-Mercado ${ }^{*}, z$ \\ Savannah River National Laboratory \\ Aiken, SC 29808, United States \\ * Electrochemical Society Active Member \\ ${ }^{\mathrm{z}}$ Corresponding author. Tel.: +1 803645 7819; fax: +1 8036528137 . \\ E-mail: Hector.Colon-Mercado@srnl.doe.gov (H.R. Colón-Mercado).
}

Platinum and platinum/nickel alloy electrocatalysts supported on graphitized (gCNT) or nitrogen doped carbon nanotubes (nCNT) are prepared and characterized. Pt deposition onto carbon nanotubes results in Pt "needle" formations that are $3.5 \mathrm{~nm}$ in diameter and $\sim 100 \mathrm{~nm}$ in length. Subsequent $\mathrm{Ni}$ deposition and heat treatment results in PtNi "needles" with an increased diameter. All $\mathrm{Pt}$ and $\mathrm{Pt} / \mathrm{Ni}$ materials were tested as electrocatalysts for the oxygen reduction reaction (ORR). The $\mathrm{Pt}$ and $\mathrm{Pt} / \mathrm{Ni}$ catalysts showed excellent performance for the ORR, with the heat treated PtNi/gCNT $\left(1.06 \mathrm{~mA} / \mathrm{cm}^{2}\right)$ and $\mathrm{PtNi} / \mathrm{nCNT}\left(0.664 \mathrm{~mA} / \mathrm{cm}^{2}\right)$ showing the highest activity. 


\section{Introduction}

Proton exchange membrane fuel cells (PEMFCs) are in the forefront of electrochemical energy conversion devices for automotive applications [1]. Despite the significant advances over the past decades, ORR catalyst activity [2] and stability [3-5] remain key challenges for widespread commercialization. High ORR activity is typically obtained through the use of highly dispersed platinum crystallites on conductive high surface area supports. Overpotentials for the ORR [5], however, limit the efficiency of the PEMFC and contribute to a high system cost. Research addressing the low activity of Pt electrocatalysts has focused on developing Pt alloys primarily with transition metals [5], with special attention to Co [6, 7] and Ni [2, 8] Pt alloys. Stability studies on Pt-alloys have led to the theory that the outer layer of the Pt alloy nanoparticles undergoes segregation and dealloying steps where the particles develop a highly active Pt monolayer on top of the alloy core. This has been shown to weaken the bond strength of the oxygen-oxygen bond relative to pure Pt $[2,6]$. This observation has led to the innovative development of highly active and stable core-shell electrocatalysts [8, 9]. The stability is attributed to increased support-catalyst interactions through an anchoring effect between the alloying element and the support which prevents particle agglomeration [4, 5] and limits Ostwald ripening $[10,11]$.

The stability of the carbon support is a critical component when evaluating the mechanisms for platinum surface area loss on the cathode. One method to improve the durability of the catalysts involves increasing the carbon corrosion resistance by increasing the degree of graphitization of carbon support, typically through the use of thermal treatments. Consequently, a reduction of the number of $\mathrm{Pt}$ nanoparticle anchoring sites results in lower performance. Carbon nanotubes (CNTs) have a cylindrical graphitic layered structure with few defects, and 
exhibit superior electrochemical corrosion resistance [12], however, the inert surface also makes adhering a uniform Pt dispersion a challenge. Functionalization of CNTs by chemical oxidation can help achieve good nanoparticle dispersions on the CNT surface; however, the mechanical and electronic properties are also altered. This ultimately eliminates the performance advantage and results in similar electrochemical stability problems that are seen with carbon black supports [13]. Nitrogen doping is another method for increasing Pt coverage on CNTs while avoiding the detrimental functionalization process using strong acids [14]. Nitrogen doping has been shown to increase the durability of Pt catalyst by providing structural defects as anchoring sites and therefore preventing metal nanoparticle agglomeration $[3,15,16]$.

In this article a simple method to prepare Pt and PtNi single crystal "needle" electrocatalysts supported on graphitized and nitrogen doped carbon nanotubes is described. Physical characterizations and the efficacy for the ORR activity in a three compartment cell are presented.

\section{Experimental}

\section{Catalyst Preparation}

Pt "needles" supported on CNT. Synthesis of the catalyst, Pt "needles" supported on CNTs, was derived from a procedure developed by Sun, et al. [17], to deposit Pt "needles" on carbon fibers. The adopted procedure was employed here for both supports, nCNT (95\% purity, NanoLab Inc.) and gCNT (99.9\% purity, Nanostructured \& Amorphous Materials Inc.). In a typical synthesis, $50 \mathrm{mg}$ of CNT was dispersed in $345 \mathrm{~mL}$ of boiling deionized water by mixing with a magnetic stirrer in combination with a titanium horn ultrasonic homogenizer (UP100H Ultrasonic 
Processor, Hielscher). After cooling the dispersion to room temperature, $1.75 \mathrm{~g}$ of hexachloroplatinic acid (99.995\% trace metal analysis, Aldrich) was added to the CNT suspension followed by $5 \mathrm{~mL}$ of formic acid (Sigma Aldrich). The reaction then proceeds undisturbed at room temperature for at least three days. The product was then filtered, washed with deionized water, and dried at $60^{\circ} \mathrm{C}$ in a vacuum oven overnight.

PtNi "needles" supported on CNT. A procedure by Deivaraj, et al. [18] was derived for the addition of Ni onto the Pt "needles" supported on CNT. Briefly, $15 \mathrm{~mL}$ of a $10 \mathrm{mM} \mathrm{NiCl}{ }_{2} \cdot 6 \mathrm{H}_{2} \mathrm{O}$ (99.9999\%, Acros Organics) was added to a well-stirred suspension of Pt/CNT (100 mg) in 140 $\mathrm{mL}$ of deionized water. The resulting suspension was heated to $60^{\circ} \mathrm{C}$, then an aqueous solution containing $62.6 \mu \mathrm{L}$ of hydrazine monohydrate (reagent grade, Sigma Aldrich) was added, and immediately followed by $626 \mu \mathrm{L}$ of $1 \mathrm{M}$ sodium hydroxide (Sigma Aldrich). The reaction mixture was stirred at $60^{\circ} \mathrm{C}$ for two hours before the catalyst was filtered, washed with deionized water, and dried in a vacuum oven at $60^{\circ} \mathrm{C}$. Finally, the $\mathrm{Pt} / \mathrm{Ni} / \mathrm{CNT}$ catalyst powder was heated at $2{ }^{\circ} \mathrm{C} / \mathrm{min}$ to $200{ }^{\circ} \mathrm{C}$ in a tube furnace for 2 hours in a $2 \% \mathrm{H}_{2}$ in $\mathrm{Ar}$ atmosphere.

\section{Catalyst Characterization}

Electrochemical measurements were conducted in a standard three-compartment electrochemical cell at room temperature using a rotating disk electrode (RDE) from Pine Instruments. A $5 \mathrm{~mm}$ diameter glassy carbon disk was used as the substrate for deposition of catalyst films and a graphite rod was used as the counter electrode. All potentials were measured with respect to a reversible hydrogen electrode (Hydroflex ${ }^{\mathrm{TM}}$, eDAQ Inc). A HCP-803 
potentiostat (Princeton Applied Research) was used to collect and analyze the electrochemical data.

Thin catalyst films were prepared according to Higuchi, et al. [19] by dispersing $4.2 \mathrm{mg}$ of catalyst powder in $12 \mathrm{~mL}$ of water and $8 \mathrm{~mL}$ of ethanol. After homogenizing the dispersion, a $10 \mu \mathrm{L}$ drop was pipetted onto the mirror finished $\mathrm{RDE}$ and allowed to dry slowly. After complete drying, $4.5 \mu \mathrm{L}$ of $0.05 \mathrm{wt}^{\mathrm{m}} \% \mathrm{Nafion}^{\circledR}$ (Perfluorosulfonic acid-PTFE copolymer, Alfa Aesar) in ethanol (anhydrous, Alfa Aesar) was then pipetted onto the catalyst film and allowed to dry. Finally, the Nafion ${ }^{\circledR}$ coated catalyst layer was heated to $80{ }^{\circ} \mathrm{C}$ for at least an hour before testing.

All electrochemical experiments were carried out at $25^{\circ} \mathrm{C}$. Cyclic voltammograms (CVs) and $\mathrm{RDE}$ measurements were performed in $0.1 \mathrm{M} \mathrm{HClO}_{4}(70 \%$, redistilled, $99.999 \%$ metal basis, Aldrich) purged with argon during $\mathrm{CV}$ collection and saturated with $\mathrm{O}_{2}$ during $\mathrm{RDE}$ measurements. Once the catalyst surface was fully activated, CVs were recorded at scan rates of $100 \mathrm{mV} / \mathrm{s}$ and then $10 \mathrm{mV} / \mathrm{s}$. Pt electrochemically active surface area (ESA) was calculated from the charge associated with the hydrogen under-potential deposition on $\mathrm{Pt}\left(210 \mu \mathrm{c} / \mathrm{cm}^{2}\right)[2,5]$ after double layer current subtraction. The ORR activity was measured by anodic linear sweep voltammetry (LSV) in an $\mathrm{O}_{2}$ saturated electrolyte between potentials $0.08 \mathrm{~V}$ and $1.1 \mathrm{~V}$ at a scan rate of $10 \mathrm{mV} / \mathrm{s}$ and rotation speeds ranging from $200 \mathrm{rpm}$ to $1600 \mathrm{rpm}$. Oxygen LSV curves were corrected for the background current and electrolyte ohmic resistance (46 $\Omega$ ) using the high frequency intercept measured by electrochemical impedance spectroscopy as described by Kim, et al. [2]. The specific kinetic current $\left(i_{k}, \mathrm{~mA} / \mathrm{cm}_{P_{t}}^{2}\right)$ was calculated from the relationship $1 / i=1 / i_{k}+1 / i_{D}$, where $i$ is the current density, $i_{k}$ is the kinetic current density and $i_{D}$ is the 
diffusion limited current density [20]. The kinetic current density was then used to generate Tafel plots by plotting the corrected voltage with the $\log \left(i_{k}\right)$.

High resolution transmission electron microscopy (HRTEM, H-9500 300kV Hitachi) was used to image the lattice fringes of the Pt "needles" and measure the particle diameter. Field emission scanning electron microscopy (FESEM, Ultra Plus FE Zeiss) was used to study sample morphology and analyze Pt and Pt/Ni distribution. X-ray powder diffraction (XRD, PANalytical X'pert Pro) was performed using $\mathrm{Cu}-\mathrm{K}$ radiation. Compositional analyses of the catalysts were performed using inductive coupled plasma-emission spectroscopy (ICP-OES) by Galbraith Laboratory Inc.

\section{Results and Discussion}

The freshly synthesized electrocatalysts show a Pt needlelike structure that is $3.6 \mathrm{~nm}$ in diameter and approximately $100 \mathrm{~nm}$ in length. When the Pt eletrocatalysts are formed on a nCNT support, the growth occurs perpendicular to the surface of the nCNT. In many instances, we observed the aggregation of needles in spherical and cubic formations, attributed to the presence of impurities (puritiy of nCNT $>95 \%$ ). On a gCNT support, growth of Pt needles seems to occur in a similar manner, however the particles do not appear to be as strongly attached to the support. Because of the high purity of the gCNT, the aggregation of the needles in the form of spheres or cubes was absent. Note that a carbon support had to be present for the Pt needles to be formed. Figure 1 shows typical FESEM and HRTEM images for the nCNT supported Pt needles. FESEM images show (Figure 1A) the coverage of the catalyst on the nCNT surface as prepared, (Figure 1B) with Ni deposited on the surface, and (Figure 1C) after 
heat treatment of the PtNi. After Ni deposition no visible changes to the Pt needle structure are observed. EDAX element mapping shows uniform Ni coverage. After the heat treatment, an increase in the needles diameter is observed. An analysis of the images shows that the needles grow from $3.6 \mathrm{~nm}$ to $8 \mathrm{~nm}$ in diameter for PtNi/gCNT and $11 \mathrm{~nm}$ for PtNi/nCNT. The HRTEM image (Figure 1D) shows the growth alignment of the fresh Pt needles on the nCNT surface. The high resolution image (Figure 1E) shows the Pt needles are highly crystalline and growth occurs along the $<111>$ as the interplanar distance between the $\{111\}$ is measured at $0.22 \mathrm{~nm}$. This is close to the reported values of $0.225 \mathrm{~nm}$ for bulk Pt crystals [21]. This results in the exposure of $\{111\}$ on the surface of the Pt needles [17, 22].

The geometry of the Pt catalyst allows for high Pt loadings while maintaining low particle size. As measured by ICP-OES, the nominal loading for the Pt/CNT electrocatalysts is $82.5 \mathrm{wt} \%$. After Ni deposition and heat treatment the nominal Pt metal loading was $70 \mathrm{wt} \%$. Assuming a homogeneous Ni distribution across the entire $\mathrm{Pt}$ needle, the $\mathrm{Pt} / \mathrm{Ni}$ atomic ratios that result from the heat treatment are $\mathrm{Pt}_{2.6} \mathrm{Ni} / \mathrm{gCNT}$ and $\mathrm{Pt}_{1.7} \mathrm{Ni} / \mathrm{nCNT}$. However the assumption that Ni concentration is homogeneous throughout the catalyst is questionable since the XRD results showed no shift to higher Bragg angles, which is indicative that Ni substitution into the Pt lattice occurs only on the surface and not in the bulk of the Pt needles $[5,6]$.

The electrochemical characterizations of the $\mathrm{Pt}$ and $\mathrm{Pt} / \mathrm{Ni}$ "needle" catalysts supported on gCNT or nCNT includes CV and RDE. CVs, Figure 2A, show the electrochemical response in deoxygenated $\mathrm{HClO}_{4}$ solution for the catalyst supported on nCNT. To aid in the comparison, the CV plots were background normalized to eliminate the double layer capacitance of the support, due to the use of the high surface area carbon black in the commercial Pt/C. The normalization allows two primary peaks to be observed, corresponding to the Pt surface reduction/oxidation 
(OR) and the adsorption-desorption of $\mathrm{H}$ on the polycrystalline Pt surface (hydrogen underpotential deposition, $\left.\mathrm{H}_{\mathrm{UPD}}\right)$.

For the commercial $\mathrm{Pt} / \mathrm{C}$ catalyst, the peak maximum for OR (Figure 2B) can be observed at a potential of approximately $735 \mathrm{mV}$. The $\mathbf{H}_{\text {UPD }}$ region (Figure $2 \mathrm{C}$ ) shows one main peak at $130 \mathrm{mV}$ with a shoulder at $200 \mathrm{mV}$ corresponding to the strong $\mathrm{H}$ adsorption on $\{110\}$. In the case of the prepared catalysts, the peak maximum for the OR shifts $42 \mathrm{mV}$ to positive potentials for $\mathrm{Pt} / \mathrm{nCNT}$ and $50 \mathrm{mV}$ for $\mathrm{PtNi} / \mathrm{nCNT}$, as compared to commercial $\mathrm{Pt} / \mathrm{C}$. This shift has been reported previously, and was attributed to reduced adsorption of blocking oxygenated species on the Pt surface which had a beneficial impact on the ORR $[6,7,10]$. The

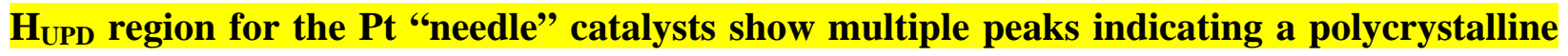
structure. It is composed of two main peaks attributed to two different Pt crystal planes available for reaction: the weakly adsorbed $\mathrm{H}$ peak at $270 \mathrm{mV}$ which corresponds to the $\{111\}$, and the strongly adsorbed peak at $125 \mathrm{mV}$ which corresponds to the $\{110\}[10,23$, 24]. In addition, the $\mathrm{CV}$ for $\mathrm{Pt} / \mathrm{nCNT}$ also shows limited evidence of an additional peak outside the range where the $\{111\}$ peak would be expected. This peak at $\sim 310 \mathrm{mV}$ can be observed when $\{100\}$ are exposed, however it is not typically desired due to its low kinetics for the ORR. After Ni deposition and heat treatment, the peak attributed to $\{100\}$ is no longer present and the $\mathrm{H}_{\text {UPD }}$ peak attributed to $\{111\}$ increased. This is significant because the $\{110\}$ and $\{111\}$ planes are the most active planes for catalyzing the ORR.

Figure 3A shows the Tafel plot using the kinetic currents for the electrocatalysts tested. The specific activities at $900 \mathrm{mV}$ are also shown (Figure 3B) and compared to that of a commercial Pt/C catalyst which had a measured specific activity of $0.22 \mathrm{~mA} / \mathrm{cm}^{2}$, a value that agrees well with the literature $[2,25,26]$. The polarization curves show specific activities for the 
Pt "needles" on gCNT and nCNT of 0.31 and $0.36 \mathrm{~mA} / \mathrm{cm}^{2}$ Pt, respectively. This value compares well with published data by Zhou, et al. [27] which reports an activity of $0.38 \mathrm{~mA} / \mathrm{cm}^{2}$ for Pt nanotubes. As can be expected, the performance of the PtNi before heat treatment is similar to that of the fresh Pt on the CNT supports. After annealing the PtNi catalysts at $200{ }^{\circ} \mathrm{C}$ a substantial increase in specific activity was observed. PtNi/gCNT $\left(1.06 \mathrm{~mA} / \mathrm{cm}^{2}\right)$ and $\mathrm{PtNi} / \mathrm{nCNT}\left(0.664 \mathrm{~mA} / \mathrm{cm}^{2}\right)$ shows an increase in intrinsic activity as compared to the commercial Pt/C $\left(0.22 \mathrm{~mA} / \mathrm{cm}^{2}\right)$. The difference in activity between the Pt catalysts with the two different carbon nanotube supports could be attributed to the difference in the Pt to Ni ratio. Wang, C., et al. [7] observed a similar activity enhancement after annealing and attributes it to element segregation that results in a Pt enriched surface over a Ni enriched subsurface. This results in an activity enhancement originating from modifying the Pt surface atoms' electronic structure and adsorption properties by the subsurface transition metal atoms. Additionally, the outer Pt layer also protects Ni from dissolution resulting in a more stable catalyst configuration.

The prepared Pt "needle" electrocatalysts are expected to have excellent stability as compared to common polycrystalline nanoparticles such as commercial $\mathrm{Pt} / \mathrm{C}$ due to the fact that the needle formation is a product of a slow crystallization/aging process. Sun, S.H., et al. has reported on the stability of star shaped Pt catalysts composed of Pt "needles" with similar dimensions to the catalysts prepared in this work. When unsupported, the star shaped catalysts were found to have extremely good stability during potential cycling [28]. However, a loss in performance was observed when the star like catalyst was supported on carbon black. The prepared catalysts in this work are expected to have superior stability due to the use of stable supports as compared to carbon black supports. Future work will evaluate the durability of the prepared electrocatalysts using accelerated durability fuel cell protocols. 


\section{Conclusions}

Nitrogen doped and graphitized carbon nanotubes were loaded with Pt and PtNi nanoneedles without additional modification of the support. The HRTEM shows highly crystalline Pt crystals growth in $<111>$. CVs show $\{111\}$ and $\{110\}$ entirely account for the $\mathrm{H}_{\text {UPD }}$ response and the OR peak is shifted to higher potentials. The Pt and Pt/Ni catalysts showed excellent performance for the ORR, with the heat treated PtNi/gCNT $\left(1.06 \mathrm{~mA} / \mathrm{cm}^{2}\right)$ and $\mathrm{PtNi} / \mathrm{nCNT}$ $\left(0.664 \mathrm{~mA} / \mathrm{cm}^{2}\right)$ showing the highest activity.

\section{Acknowledgements}

The authors would like to acknowledge the University of South Carolina Electron and Clemson Microscopy Centers for instrument use, scientific and technical assistance. This work was funded under SRNL FY11 LDRD Program. Savannah River National Laboratory is operated by Savannah River Nuclear Solutions. This document was prepared in conjunction with work accomplished under Contract No. DE-AC09-08SR22470 with the U.S. Department of Energy.

\section{References}


1. Gasteiger, H.A., S.S. Kocha, B. Sompalli, and F.T. Wagner, Applied Catalysis B-Environmental, 56, 9-35 (2005).

2. Kim, J., S.W. Lee, C. Carlton, and Y. Shao-Horn, Electrochemical and Solid-State Letters, 14, B110-B113 (2011).

3. Chen, Y.G., J.J. Wang, H. Liu, R.Y. Li, X.L. Sun, S.Y. Ye, and S. Knights, Electrochemistry Communications, 11, 2071-2076 (2009).

4. Colon-Mercado, H.R., H. Kim, and B.N. Popov, Electrochemistry Communications, 6, 795-799 (2004).

5. Colon-Mercado, H.R. and B.N. Popov, Journal of Power Sources, 155, 253-263 (2006).

6. He, Q.G. and S. Mukerjee, Electrochimica Acta, 55, 1709-1719 (2010).

7. Wang, C., D. van der Vilet, K.C. Chang, H.D. You, D. Strmcnik, J.A. Schlueter, N.M. Markovic, and V.R. Stamenkovic, Journal of Physical Chemistry C, 113, 19365-19368 (2009).

8. Li, W.Z. and P. Haldar, Electrochemical and Solid State Letters, 13, B47-B49 (2010).

9. $\quad$ Gong, K.P., W.F. Chen, K. Sasaki, D. Su, M.B. Vukmirovic, W.P. Zhou, E.L. Izzo, C. PerezAcosta, P. Hirunsit, P.B. Balbuena, and R.R. Adzic, Journal of Electroanalytical Chemistry, 649, 232-237 (2010).

10. Komanicky, V., K.C. Chang, A. Menzel, N.M. Markovic, H. You, X. Wang, and D. Myers, Journal of the Electrochemical Society, 153, B446-B451 (2006).

11. Chen, Z.W., M. Waje, W.Z. Li, and Y.S. Yan, Angewandte Chemie-International Edition, 46, 4060-4063 (2007).

12. Zhu, W., J.P. Zheng, R. Liang, B. Wang, C. Zhang, G. Au, and E.J. Plichta, Journal of the Electrochemical Society, 156, B1099-B1105 (2009).

13. Saha, M.S., R.Y. Li, X.L. Sun, and S.Y. Ye, Electrochemistry Communications, 11, 438-441 (2009).

14. Chen, Y.G., J.J. Wang, H. Liu, M.N. Banis, R.Y. Li, X.L. Sun, T.K. Sham, S.Y. Ye, and S. Knights, Journal of Physical Chemistry C, 115, 3769-3776 (2011).

15. Jafri, R.I., N. Rajalakshmi, and S. Ramaprabhu, Journal of Materials Chemistry, 20, 7114-7117 (2010).

16. Zhou, Y.K., K. Neyerlin, T.S. Olson, S. Pylypenko, J. Bult, H.N. Dinh, T. Gennett, Z.P. Shao, and R. O'Hayre, Energy \& Environmental Science, 3, 1437-1446 (2010).

17. Sun, S.H., G.X. Zhang, Y. Zhong, H. Liu, R.Y. Li, X.R. Zhou, and X.L. Sun, Chemical Communications, 7048-7050 (2009).

18. Deivaraj, T.C., W.X. Chen, and J.Y. Lee, Journal of Materials Chemistry, 13, 2555-2560 (2003).

19. Higuchi, E., H. Uchida, and M. Watanabe, Journal of Electroanalytical Chemistry, 583, 69-76 (2005).

20. Paulus, U.A., T.J. Schmidt, H.A. Gasteiger, and R.J. Behm, Journal of Electroanalytical Chemistry, 495, 134-145 (2001).

21. Hanawalt, J.D., H.W. Rinn, and L.K. Frevel, Industrial and Engineering Chemistry-Analytical Edition, 10, 0457-0512 (1938).

22. Chen, J.Y., T. Herricks, M. Geissler, and Y.N. Xia, Journal of the American Chemical Society, 126, 10854-10855 (2004). 
23. Markovic, N., H. Gasteiger, and P.N. Ross, Journal of the Electrochemical Society, 144, 15911597 (1997).

24. Watson, D.J. and G.A. Attard, Surface Science, 515, 87-93 (2002).

25. Gong, K.P., D. Su, and R.R. Adzic, Journal of the American Chemical Society, 132, 14364-14366 (2010).

26. Koenigsmann, C., W.P. Zhou, R.R. Adzic, E. Sutter, and S.S. Wong, Nano Letters, 10, 28062811 (2010).

27. Zhou, H.J., W.P. Zhou, R.R. Adzic, and S.S. Wong, Journal of Physical Chemistry C, 113, 54605466 (2009).

28. Sun, S.H., G.X. Zhang, D.S. Geng, Y.G. Chen, R.Y. Li, M. Cai, and X.L. Sun, Angewandte Chemie-International Edition, 50, 422-426 (2011). 

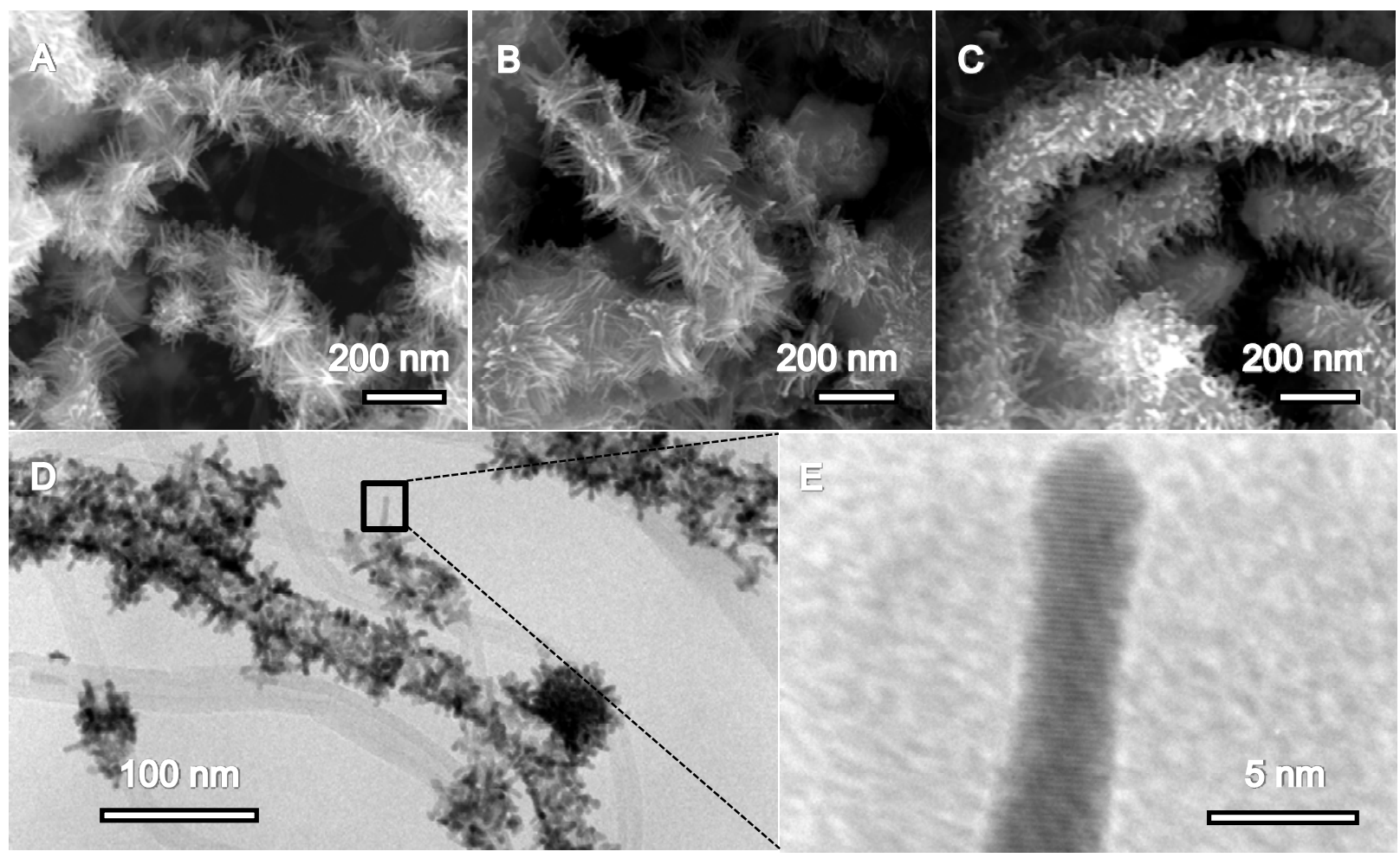

Figure 1 FESEM image for the nCNT supported Pt needles: (A) coverage of the catalyst on the nCNT surface as prepared, (B) Ni deposited on the of catalyst surface, and (C) after heat treatment of the PtNi. The HRTEM image (D) shows the growth alignment of the fresh Pt needles on the nCNT surface. The high resolution image (E) shows the Pt needles lattice fringe. 

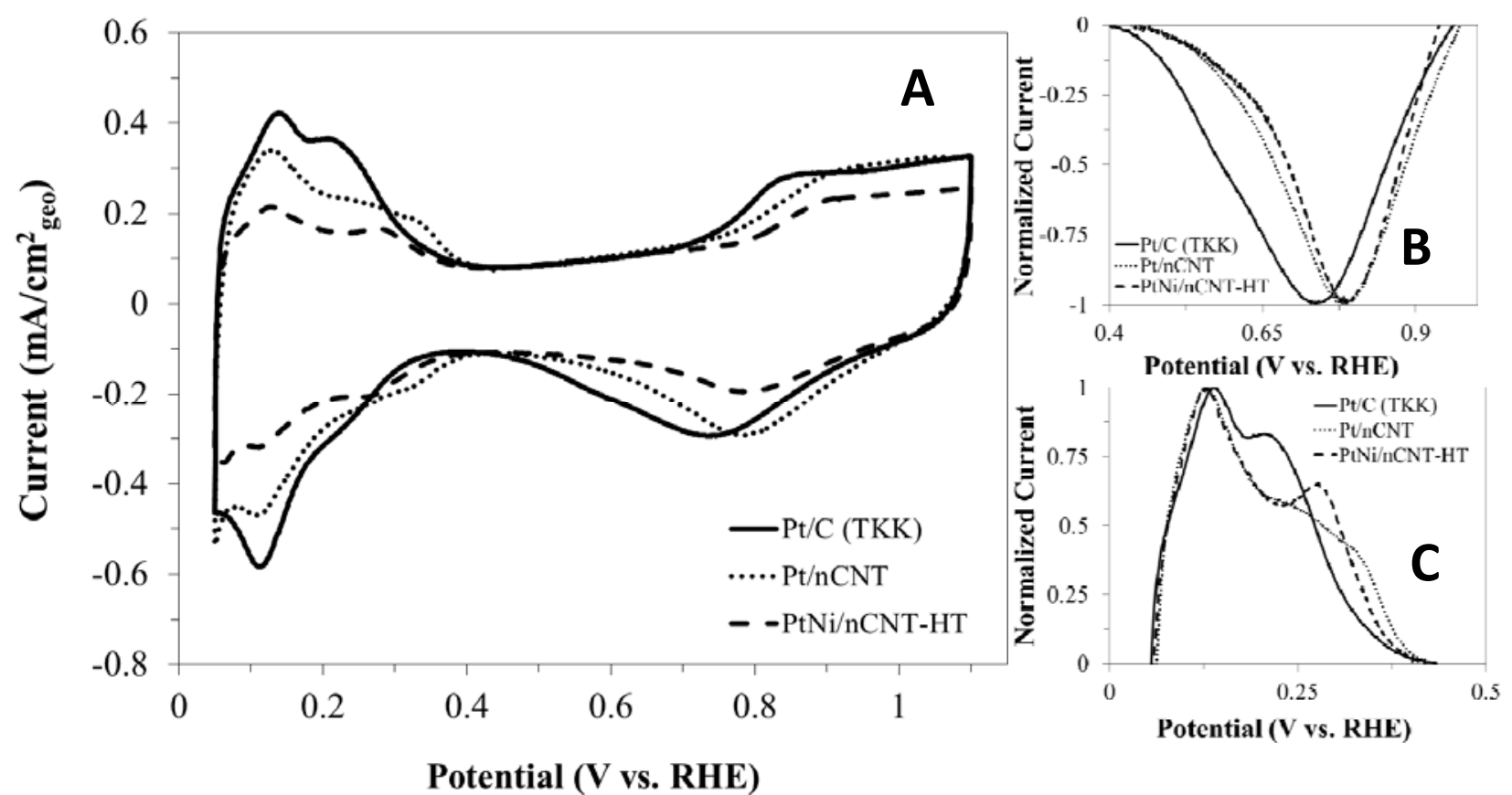

Figure 2 Typical electrochemical response in deoxygenated $\mathrm{HClO}_{4}$ solution for the catalysts supported on nCNT (A). For clarity, the Pt oxide reduction peaks (B) and the $\mathrm{H}_{\text {UPD }}$ region $(\mathrm{C})$ on the prepared catalysts are shown separate. 

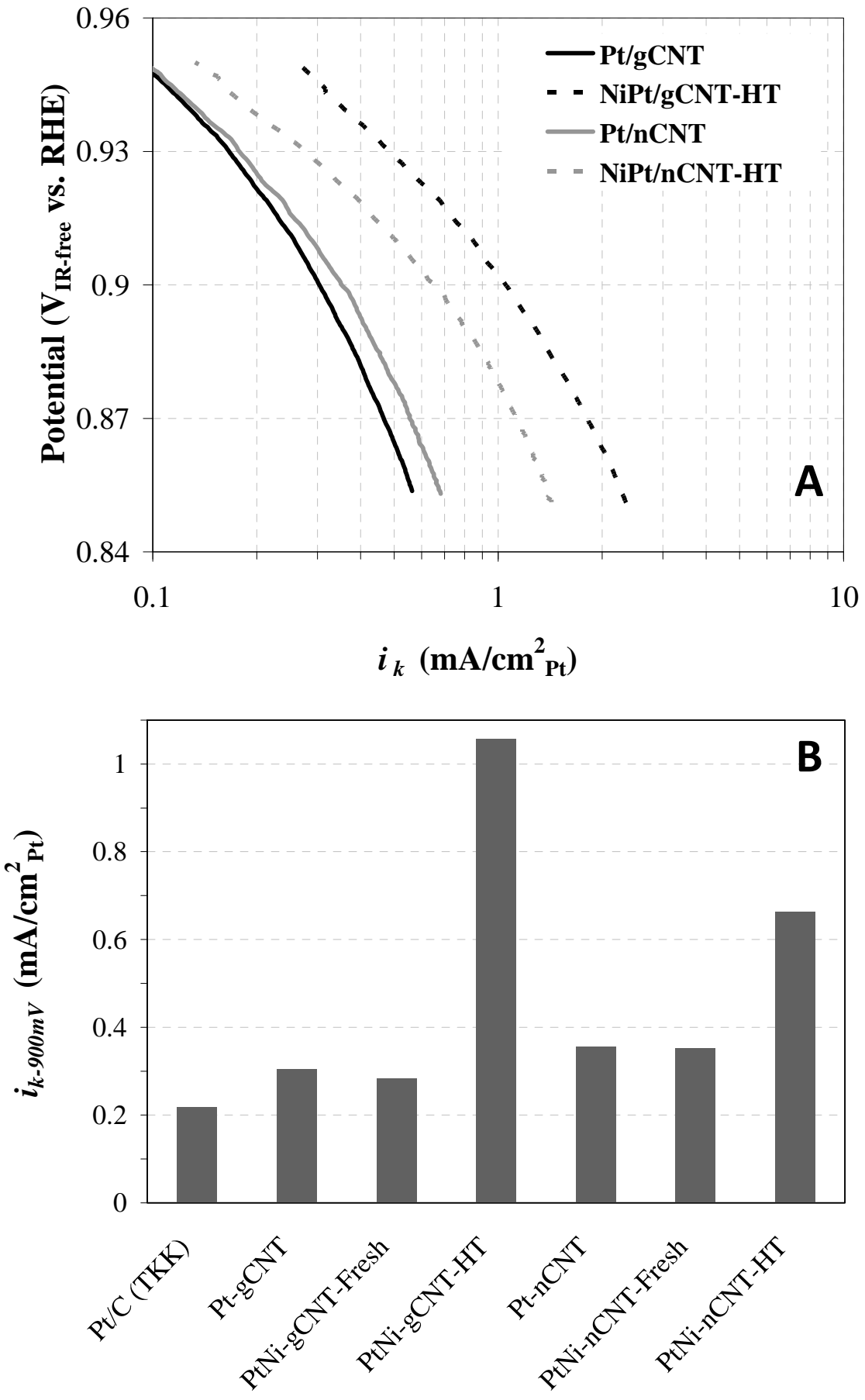

Figure 3 ORR intrinsic activity as a function of iR corrected potential at $800 \mathrm{rpm}$ (A) in oxygen saturated $\mathrm{HClO}_{4}$ solution. (B) Comparison of the specific activities at $900 \mathrm{mV}$ and compared to that of a commercial Pt/C catalyst 